The International Conference : Cities' Identity Through Architecture and Arts (CITAA)

\title{
The invisible in painting art between east and west
}

\author{
DOI: $10.21625 /$ archive.v1i1.132
}

Hosam Abd Elkader Metwally Mohamed ${ }^{1}$

${ }^{1}$ Assistant professor; depart painting; faculty of fine arts; helwan universty;egypt.

\section{Keywords}

Visible; Invisible; East; West.

\begin{abstract}
The Art of painting relies on the employment of the painting's vocabularies in an idiomatic meaningful format under the framework of the dialogue form. Such methodology occurs at times and in a new style to create new systems and formats at other times (Form Structure). The dilemma lies between these two frameworks where there are reality and mind, sensory and mental or visible and invisible, that is, between what is perceived by the eye of idiomatic semantics forms and what is realized in accompanied suggestive or figurative meanings.
\end{abstract}

The interpretation of the invisible in the vision of Oriental Art is different from the vision of the western art because the spirit of the culture is manifested in the first to incorporate the individual in the group. As in the universe, it removes intervals so that the individual may seem similar to his surroundings in order to reach the infinite and unlimited aspect. This vision is based on a type of intuitive knowledge in the form of detection or discovery, which is based on the dualism of the visible and the invisible. Therefore, the receiving process is unlimited to the aesthetic pleasure that focuses on the form alone, and it is an existential process that is based on the dialogue between the receiver and the artwork. Islamic Sufi aesthetic thought tries to find the sensory effects in the universe. It is not concerned with the mental abstract perceptions of geometric shapes associated with the western logic." Islamic abstraction would not seek to meet the formal requirements such as a mathematical current of Mondrian or freeing the spirit of the form exracted from the content, internal necessity of the structure or the internal empathy for the colors and meanings. It does not intend to reach ideal purity in the form so as to realize the artistic feeling in Malevich. It tries to find natural laws, including geometric shapes ,and then its loads them with facts and meanings towards the absolute. It results in a new standard vision that will create another independent reality which does not end with just watching the painting so as to combine the idea with the artistic vision to denote the meaning"(Abu Elmaggd, 2011).

The research problem: It lies in the answer to the question 'What is the role that the invisible plays in paintings; as it is considered a spiritual connection language between the artwork vocabularies and the receiver.

Research Methodology: The analytically critical method.

Research limits: This paper deals with the philosophy of vision as an equivalent art to the invisible between East and West- through the study of some artworks which shows this idea in human civilizations.

The importance of research: It tries to discuss a set of points: Visible and invisible as a term and concept, to track the movement of the interpretation of the invisible through some Eastern and western civilizations, the relationship of space in the artwork with the invisible, 


\section{Introduction:}

The artist has been obsessed with the concept of the invisible all over the course of history. He believes that the universe has hidden forces requiring sacrifice in order to know and get close to them until he can reach a totalitarian -and whole as a kind of- salvation. Ancient Egypt and Mesopotamia civilizations are the oldest human civilizations as they made progress in arts and architecture. They had a special concept for the interpretation of the invisible worlds, for many of which relied on the presence of metaphysics or the godly powers. Most of the Arts have dealt with sacred ideal framework embodied in legendary forms and bodies with a character, sometimes in combination of human and animal elements moving toward the spiritual - the essence. Both civilizations did not give importance to a similarity with the realistic form as far as to attempt to explain the phenomena, so that forms, as they were, became symbols seeking the invisible, like the Sphinx in Ancient Egypt and the winged bull in Ancient Iraq.

The Greek philosophers were inspired by them in the quest for the dialectical relationship between the visible and the invisible:" Talis (624/546 BC) believed that water -by which the universe was created- was the hidden invisible force, whereas Pythagoras (580/500 BC) found that the idea of the invisible is manifested in the development of mathematics through the language of numbers and their idealism and philosophy with its interpretation in legendary views. However, Heraclitus (544/483 BC), believes that the invisible was crystallized through opposite conflict and fight which were renewed to become visible. Plato (428-347 BC), found ideal ideas in the mathematical formulas which were near to the invisible and far away from the visible- where the geometrical shape owns in his concept an absolute beauty, intense in itself, is higher than the visible. According to his perception, it was necessary for the formation of the moral order which is synonymous with the idea of goodness and beauty. On the other hand, Aristotle ( 348-322 BC) employed, not engineering and mathematics, but an analytical mental thinking to interpret the invisible, so it was incarnated in the tangible material and it became visible. Thus, he found in the matter a tremendous energy and a great means to express the invisible the unlimited"(Almusawi, 2005). However, the idea of the invisible may be embodied and maximized in the Islamic arts, which is originated and returned to God as He is the absolute and totalitarian beauty as well as the primary source of existence and creatures.

Therefore, they abandoned the similarity with tangible materials and turned towards manifestations. The abstract in lines and shapes extends to include symbols and hints of ideas and meanings which are not unknown for those who understand the Islamic art. The Muslim artist treated the visual arts on the basis of intellectual perceptions, where he paints what he knows, not what he sees, or he expresses the thing and he does not transfer it". as IbnArabi (1165-1240) says: "the outwardly and inwardly are twin brothers inseparable, if one of both is known the other is known". Some philosophical views on this subject have appeared in modern times such as Maurice Merleau-Ponty (1908-1961), who believes that the invisible is not the antithesis of the visible. The visible possesses a part that is invisible, since the meaning and metaphoric significance can not be seen but can be felt. It is worthy of mentioning that every effort is made to see them working on to hide them although they are located within the visible as a strategy in the formal structure"(AbuElmaggd, 2011).

\section{Terminology:}

The dilemma: a confusing problem. Kant (1742-1804) says: that the provisions characterized by Forms are the provisions where the affirmative and negative are possible, and its mental belief is based on the judgment. The Visible: it is everything relative and changeable that could be measured and could be a standard of judgment. It is the variable that makes the receiver turns to the invisible. The invisible (to see Vision) is the mental model of Plato, which is the image of the invisible. However, Aristotle says that it is the one who interferes in the formulating of visible, and it is the hidden force and the artist's imagination which changes the nature of objects and bodies. Hegel (1770-1831) defined the invisible as an absent idea by which the artist can turn it into the visible, which is an identical perception of an abstract object from the necessities of nature. It is about the content and conditions of the outside realization. The invisible is also an independent, complete in itself and nonrelative. Also, it is a constant indicating the infinite, and it does not depend on something else other than itself. The invisible creates all the existence.

\section{Ancient Egyptian Civilization}

(Akhenaton as a model).The art of painting is demonstrated in the ancient Egyptian murals, especially in the era of Akhenaton, who was looking for the mechanism of turning that idea of the metaphysics into the visible 
presence through the used raw material mold. Groups of artists relied on experimentation and interpretation the idealism form for the purpose of access to the un-similarity - and the unlimited. They produce artistic images which are neither quoted from the external reality nor are the perfect interpretation of the self, that of the King, but it is an offloading of the emotional charge generated by the fusion of existence in the imagination of the artist. It is what led him to a mystical knowledge so that the images and statues seem as if they are alienated. Such notion could be extracted from the face of Akhenaton speared in ( fig. 1) with this elongation form with the almond eyes, extended nose and drooping mouth. The aesthetic discourse is inspired by his emotional ownself instead of the realistic form as a result of the artist's availibility and freedome at the time. Other pictures and statues appeared different from the visible reality where the sensory and intuitive argumentation are realized and perhaps reminiscent of expressionist models of Modigliani, the painting of Jesus Christ for the German Noldh or a painting during the early period of Picasso's cubism. The most important characteristic of the era of Akhenaton is the manifestation of simplification and reduction by which the form-combinations stands out of working or activating the mental images.

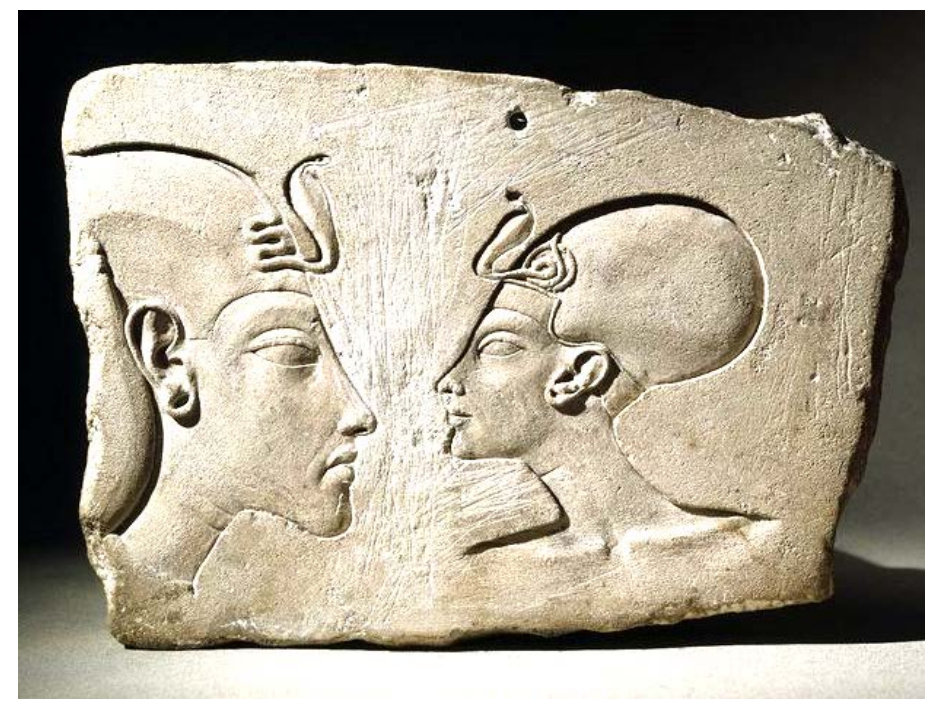

Figure1 The witbour plaque,Museum relief; Akhenten\&Nefertiti,13521336 BC,broooklyn.

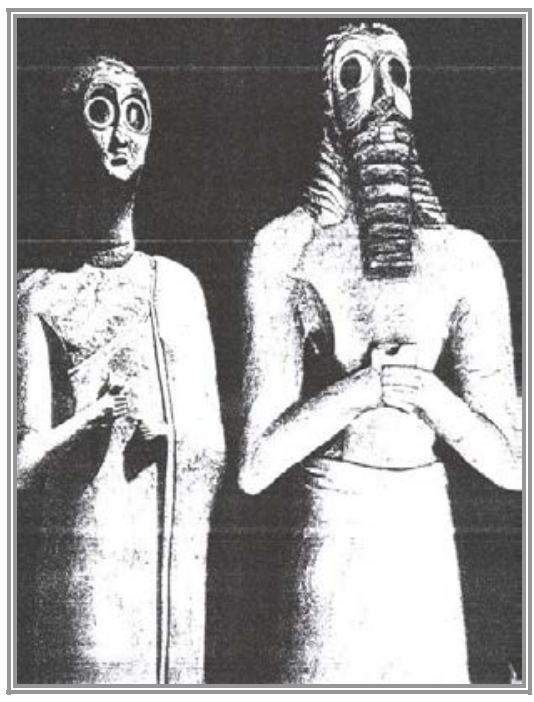

Figure 2 The God Abu \&his wife, Iraque musueum,300 BC.

The artist was not totlly concerned with the visual details, but rather the artist was more into translating the meaning and significance of the vision through a deep understanding according to constant laws and concepts that assist in bringing about the material into a perfect and idealistic place, that is, the symbolic world. The ancient Egyptian artist replaced the visual image with an eternal one, which does not accept any changes in the world of eternity. That idea is associated with the effectiveness of the analogical magic where the image works here as a magic mediator in order to restore the structure system of the normal life into another environment, having the status of stability and immortality. This concept is enhanced by the origins of the heavenly King and his cosmic ability, prompting the artist to be diligent in working hard to provide the equivalent of that invisible meaning through the distribution of the artistic elements on the work surface. For example, the used color extends in uniform in all directions and is not based on the principle of shades, or hues. It also moves away from the bright color so that perspective-relationships include a variety of linear designations, and a visual equivalent is created between the work surface and the space to achieve a kind of emotional representation. Accordingly, it dominates the images of the characters by abstract attitude that cut their contact with time and place in order to move into a dreaming world that reminds the viewer of the Japanese drawings and (Tanagra) small classical statues"(Alhamedi,2012). It is worth mentioning that the ancient Egyptian combined the material and the spiritual trends ,side by side, where he resorted to subduing the elements of nature with its manifestations. Making identical copies of the original statues were also another way conveying his auto response to the world around him. However, he seeks the totalitarian and the universal aspects by trying to penetrate the phenomena for embodying the conceptual meaning of the new spiritual reality at that era. The major reason behind that was his belief in the importance of the essence in building forms and constructions.

\section{Mesopotamia:}

The old Iraqi artist realized that unraveling the mystery surrounding the invisible needs obtaining the truth that is tantamount to achieveing his safety- as the visible reality does not provide him with sufficient answers. He thinks that every- thing or phenomenon has a spirit or hidden God among the gods that were later divided into 
six levels: heavenly, earthly, sexual, animal, human and godly composite. Therefore, the artist tried to be connected with invisible higher objects responsible for this universe, and he expressed it in the way of a legendary form aiming to worship those invisible powers, along with controlling the various manifestations of nature. in that light, the abstract compositions and statues became much distant from visual simulations, while the attention focuses on creating continuous and direct relationship between humans (Visible) and the Gods (invisible).Thus, he can transverse the fictional world of ideas and myths, that the artistic compositions seem strange without any relevance to the world of visuals as in (fig.2), which represents the statue of ( the God Abu and his wife). It is dated back to the year $3000 \mathrm{BC}$, and they were standing in a state of devotion and worship to the forces of the divine (the invisible). These are noticed in the clenched bodies which are preparing to embark on projects, while seemingly cut off from the outside world through combinations of wide goggled eyes. The expressive style may be shared in liberating the visible form (human) so as to be united with the divine form (invisible). Therefore, sublimity of the supernatural appeared on the statue that includes artistic features, like flatness, simplification, hybridization and inlaying with precious stones until it appears with a new form outside its known limits.

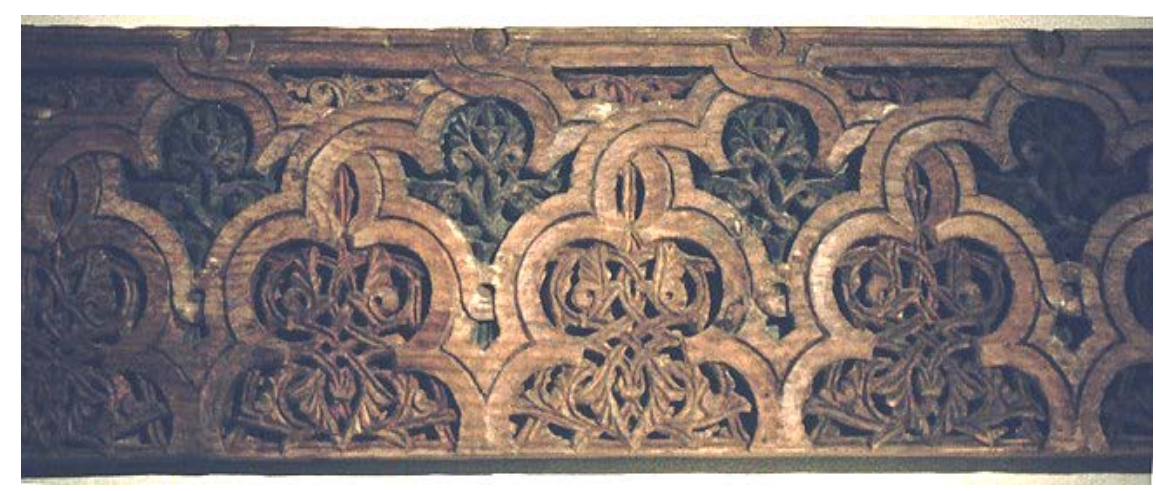

Figure 3.One of collections of Islamic art , Paris .

Slamic Art: Islamic Art is united in its essence, in spite of the emergence of minor changes in countries where Islam entered. It is perhaps that the character of the Transfiguration and the transcendence of the analogy is attributed to the divine order (invisible) is the origin of the creatures where his ability are reflected in the small atom nucleus as equally as in the great galaxy. This vision, as it is, needs to the continuity of the receiver and interrupting the dialogue between the eye and the mind of receiver. It is difficult for any-one to understand the origins of Islamic Art, without this vision, thus his philosophy becomes far away from the visual formation . Therefore, Muslim artists realize that relationship which combines the eye and the mind and comes from his being aware of the signs, symbols and gestures across the joined lines and spaces that make the picture far from spontaneous visual so as to compose another internal image (invisible) . "Al-Ghazali mentions in this regard: "the eye can recognize of the things their manifestations and top surface without their interior, and their molds and images but not their essence. The mind can penetrate the insider and secrets of things, realize their truths and spirits, and devise their reason, cause, end, purpose and wisdom as well as from what they are occurred, how they are created, how much meaning they are combined, on which level they descend, what their ratio and their percentage to other creatures". Thus, the eye is considere an extension to the mind and its function is an extension to the function of the mind. The artwork is directed here to the eye as a way reach up to the viewer so as material image can move to the human brain and then self internals which are able to interpret and perceive making the field of vision to continue without interruption and finishing with the end of the vision. The combination of sensory and intuitive through conversion of the form is necessary to create the relationship between the signifier and the signified to reveal by subtly expression the invisible forms and unconscious sensations which are difficult to be expressed in pictures and words"(Abd Elazize, 2006). As a result, these barriers are crashed in the visionary of the artist that the universe with its manifestations and phenomena become a single unit. Islamic Art is based on abstraction, which marred with the mystery along with the regeneration process through repetition, symmetry, harmony, movement and rhythm in order to the viewer's eye moves from the visible to the perceived (fig.3). According to the Jestalt theory, perception of things is occurred entirely, then the parts and details, as the mind of the viewer tends to see parts of the picture as a whole then turns him into details so as to complete the image mentally and extends to add missing parts and lost details by the experience and culture of the artist. Looking at the artwork requires effort when you see visible things that are not obvious at first glance as the existence of circles, squares and duplicate units which push the viewer to try to imagine or realize the vision of unseen things. Thus, the visible is transformed into invisible and this does not depend on a single axis in the vision but the viewer's eye seems in a state of continuous movement when more than mental image enters quickly the cerebral cortex in order to address the mind and conscience together. 
Isthmus: Ibn Arabi says:" "the levels are three: outside, inside and in-between which distinguishes ,the outside the inside, and separates them. It is the isthmus which has a face to the outside and another to the inside but it is the same face which cannot be divided. Thus the relationship between the outside and the insideis on the level of knowledge is not the differentiation of the existential relationship but the differentiation of knowledge for an existential fact"(Abu Elmaggd, 2011) .

Al-Ghazali, in this regard, mentions in the theory of epistemology: "that there is in the known a fraction of the unseen. The knowledge is coupled with the unseen and what we know in some science is just the least little. What we do not know is the origin and the whole essence so that there is an intermediate state between the dualities (visible and invisible), (known and unknown) or ( evident and hidden) which are similar to the isthmus. The isthmus represents a state between two parties which can meet and separate at the same time but both of them do not meet with one face but several faces leading to the dynamics of the life. However, the surface appearances do not represent or tend to stabilize as what we see and feel does not necessarily reflect the truth that is broader and greater than that. Thus, the isthmus is the greater bearer for the dynamics of phenomena and their multiple manifestations. Muslim artist has drawn his mystical Sufi and knowledge view across the overall vision of the existence states and perception of life. Music has been also connected to the world of the unseen, the invisible.

Space and invisible (space is relative and fullness is absolute): space in eastern artwork isnot less significance and important than the whole music of the world or creatures as well as the moral isthmus and the significance of metaphors. "In Buddhist artworks and meanings, the artistic space is considered a synonym for meditation, while making the area of the space much full is the interpretation by the artistic sense in Chinese paintings, especially in the (tao) like (fig.4) as well as in the Japanese paintings"(Abd El aziz, 2007). However, the state of transcendence or promotion for not to be similar to tangible materials by filling most of the space in the Islamic Art. The fear of believing in the evil infused in them ensues saying that the space and the way of filling it are equivalent to the meaning of the invisible in the art of painting.

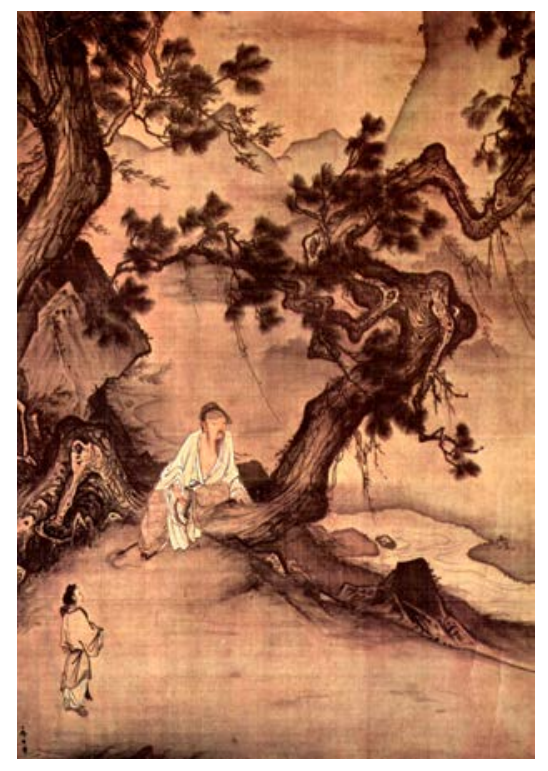

Figure 4 Wall scroll painted by malin,1264;ink on silk,110 cm wide.

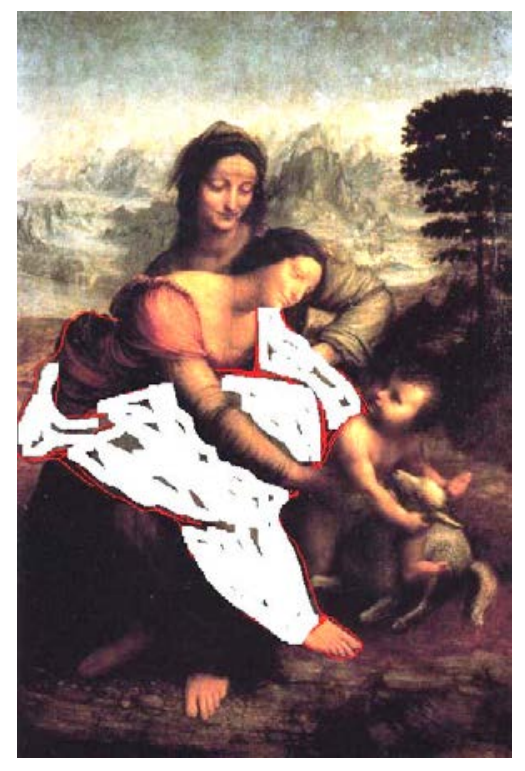

Figure 5 Leonardo da venci,The virigin\&child with st,Anne oil on wood, $168 \times 130 \mathrm{~cm}$, Louvre museum.

Western view: the illusion that there is a third dimension is synonymous with the invisible in the European art. Leonardo Da Vinci relies in many of his paintings on the juxtaposition of music with painting in order to make the connecting formula with the manifestations of nature.

Freud stated in his book (psychoanalysis and art) about the truth of the art as an expression of sub-consciousness of the man, and when he saw an exhibition of Leonardo, he wrote: "The effort to write a biography, if he really sought access to understand the psychological life of the hero it should not (.... ) pass in silence of the sexual activity or sexual secrets of the person in question. "When Freud read the novel (Leonardo eagle), in which he came to him in the cradle and opened his mouth with his tail and hit him on his lips, only that Freud can discover , through the interpretation of some of the work of Leonard, that he had been an incident of homosexual assault in his childhood, so that his most important works (figure5) (the Virgin and child with St Anna) bears in 
its contents the symbol of the Eagle where it includes sad colors, such as the painting of (Mona Lisa), and in that, there are indicators to access to the subconscious side of the artist Leonardo"(Elnivar, 2013).

There are some realistic artworks that contain what is beyond the purpose and the meaning including an example of the painting (the origin of the world) (fig.6) of the painter Gustave Courbet, in which a naked body of a woman shows without a head, a neck without a leg, very thick haired vagina (Faraj) and part of the right breast appear in the middle of this body.

The view of Courbet is that vagina represents the origin of the desire by which all mankind are born. He intends to paint the vagina as wide open to enable the viewer's eye to see it, as well as the vagina itself, takes the shape of the eye so that Courbet can depend on the reciprocal relationship between this form and the viewer's eye. He acknowledges the fact that the vagina can see us and reveals our - humans - decadent features. Courbet also wants his portrait to have an eye to see the others.

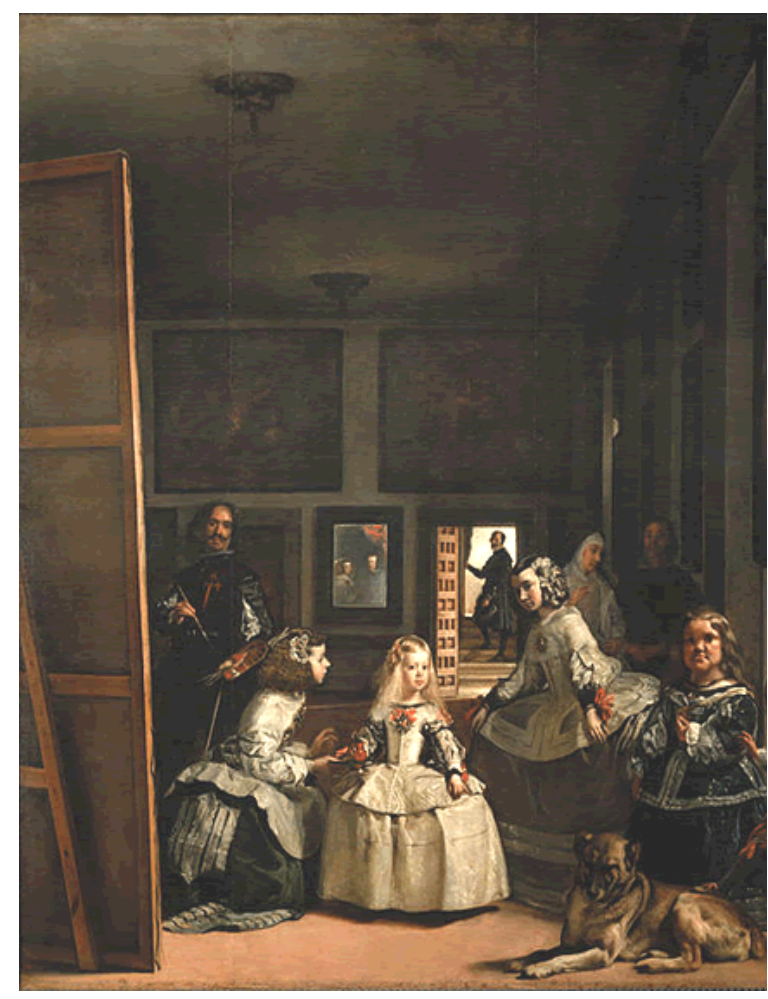

Figure 7 Velasquez, maids of honor,1656; oil on canvas museum of madrid, $318 \mathrm{~cm} \times 276 \mathrm{~cm}$.

Mirror and invisible: the mirror does not only reflect the image of the person throughout history, but also his relationship with his surroundings. It contributes with a great in highlighting the ambiguity and contradiction that the man is incurred when he contemplates upon it.

It is possible that the mirror can reflect invisible parts through the creation of extra dimensions in the painting as what has been achieved in some of the paintings of some artists such as Van Eck and Georageony. "They may express the pride and flashy as in the painting (the basic seven sins) of Jerome Bush in 1500.

The mirror, in other artworks, may express some (invisible) virtues as we see in the work of Giovanni Bellini (the face of a young woman with a mirror) in 1515. During the 19th century, the mirror image has acquired the artworks of Manet, Monet, Renoir, and Lautrec as well as others. Even in our modern times, the mirror and its presence in the artwork differ from previous concepts and meanings. Looking at the mirror has become a matter of concerns and fears, with the progress of arts, media, and photographs, because it reminds the person of his previous features of youth which was definitely more beautiful"(Sharaf, 2013).

Among the most important artists who take the mirror in their paintings, Velasquez in his work named (maids of honor) (fig.7) in which the face of the enlightening painter and his dark stature appear in-between a visible part and another invisible one- thanks to the pictorial pose. The eyes of a painter stare at an invisible point, that is our faces, us the viewers, and perhaps heading outside of the painting towards the space in front of him. The viewer and the seen image exchanged here their roles without interruption, as there is no stability at a fixed position, but 
the ongoing conflict between the self and the subject of the painting on the one hand and the viewer with the painting model on the other hand. It is where they exchange their roles until infinity. In addition, there is $\mathrm{s}$ form in the background that represents an upside down painting which we do not behold its back, so it is meant to give a sense of wonder- are we the viewers or the viewed?

"The mirror presence becomes a stranger in this work as it does not reflect anything of the reality, not the painter nor the persona in the middle of the artwork (Princess Margaret and Chaperones), and it conceals more than it reveals. As if it is a symbolic embodiment of the spirit, it may seek the mental presence of the painting elements (invisible) in exchange for the physical presence (visible)"(Mohamed, 2015).

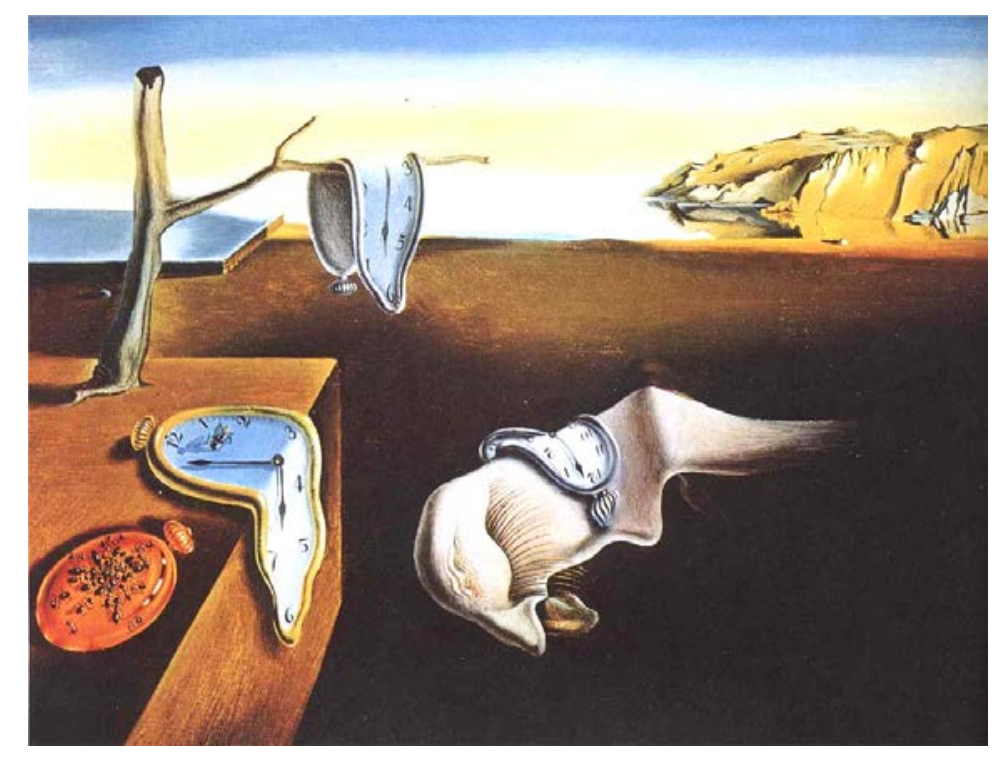

Figure 8 Salvador dali, the persistence of memory,1931, oil on canvas, $24 \times 33 \mathrm{~cm}$ modern art museum.

Surreal paintings are used to portray realistic things to express their dreams and improve the natural forms to be above the visible reality, as we find in (fig.8). so, as to be close to the invisible, as a result of converting elements to symbols that lay the problem of the relationship between the symbol and the sign that does not exceed the scope of the understood signal by the viewers. It is easier in that sense because it goes directly to the viewer's eye making it easier to be interpreted and anayized. The symbols are more complex or abstract and cannot be understood unless through realizing its core idea, as they are divided into two parts: general symbols and private ones, The second contains the art of critics which is interesting because the Western art is nothing but an expression of personal thoughts and emotions.

It is difficult to interpret the multiple indicative dimensions of the general symbols as a result of the correlation of the plastic symbols with their creator. In order to decipher their code, it is necessary to refer to the artist himself.

The world of the symbol in the surreal logic poses a dialectical relationship with the concept of implication in the art expression that is not constrained by borders or a unified law. However, the symbol gains freedom which suits and composes with creative self.

"The association of the symbol with the world of fantasy makes it seeks for the nothingness and the unknown. What is this thing, this fragile, this infinite, the dream is the truth of the reality and the possible whitch can be imaginated to us in the form of illogical hissings, the weak internal visiting fly, scattered of multi formless according to the saying of Mahmoud Darwish(1941-2008) However, when we contemplate in theses dialectical topics it can be discerned that the impossible, the absurd, the infinite and invisible can be formed within the dream circle"(Abd Elaziz, 2002). 


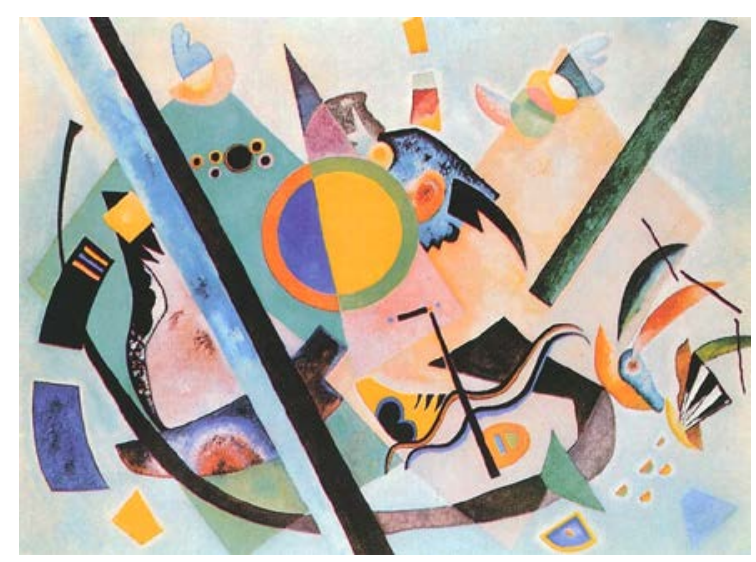

Figure 9 Kandinsky, multi colored circle,1921, Yal university, Art gallery, oil on canvas, $77 \times 101 \mathrm{~cm}$.

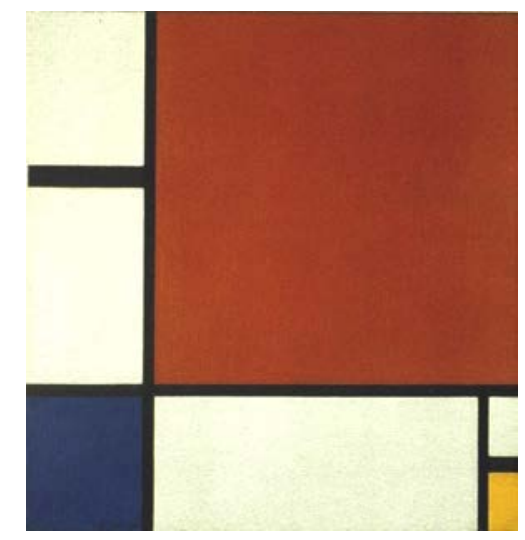

Figure 10 Monderian, composition with Red Blue, Yellow 1930, oil on canvas, metropolitan museum of art.

With the abstract of both Kandinsky and Mondrian (figs. 9.10), they have a different point of view, where the first sought to dismantle the image of the visual shapes and re-launched it again to introduce signifier. He managed to do so without designating signifed that has a consensus. In spite of the fact that the signified lies inside the shape, it is subject to special artistic codes related to the artist, Kandinsky himself. In other words, the interpretation and perception of the artwork stemmed from the relative mood of the viewer and the process become closer to the phantom. Kandinsky tried to reach it by an abstract means and presented an interpreted world that is unknown and unspecified in the lower limits of the perception. It is a new language but without the alphabet.

Mondrian has known the end or a finite world which has a mathematic construction representing the metaphysics. In such world, the signifier is represented -here- in geometric shapes, and it corresponds to the signified (metamathematic construction ). Thus, the interpretation and metaphor area between them was shrinked due to the fact that he had similarities between the starting point with the end or the means with the aim. This view is different from the Eastern or Islamic vision that is not relative to the visible framework, even if it is found, it is just on the surface only because the internal or the inside does always refere to God (the Almighty).

Therefore, the artwork becomes a signifier with a metaphysical signified which reaches up to the viewer in a way not embodied or imagined. This is found in the Islamic Art through figurative visual signifier synonymous to the meaning of the word and the image by abstraction, while in modernist abstraction, is associated to and coincided with the Western civilization crisis. The crisis that was about to explode in a collision with general art technology and the loss of the unity of reference. These are the most important reasons were the separation of religion from the art and science lead to the dispersion of the standard vision and the general concepts. Not to mention that these concepts govern the relationship between humansbeing and the manifestations of the universe in addition to the multiple frames of reference- for each school of art and for every artist.

The preoccupation of the artists in the modern era with the invisible worlds perhaps coincided with the emergence of diseases, psychological problems, and complicated human conditions, prompting some artists to try to think of his artistic production such as the Colombian "Fernando Botero"(1932-?). Botero's artworks rely on amplifying human bodies in order to create a sense of intensity in a cynical manner that is closer to a childish or caricature sense. His creations combined sobriety of classicism and contemporary: he extracts the first through periods of his stay in Italy and Spain. The second appears with a tinge of classicism that is spreaded in many of his artworks, such as (fig,11) in which figure and laughing faces are similar to balloon bodies because of their fatness. He abandons the visible form and dives into his world and their worlds on an equal footing. His philosophy probably implies several meanings; however, the exaggeration wonders aimlessly on fleshy bodoes and faces, which the features cannot cope with. The artist sympathized with them because their present sizes were their roles; small and limited in this world. The origin of his vision is the family and its social behavior which are formulated in visible templates bearing invisible characteristics so that social and psychological projections are generated on the persona of the prosperous bourgeois society at the expense of the misery of the poor starving classes in the society. 


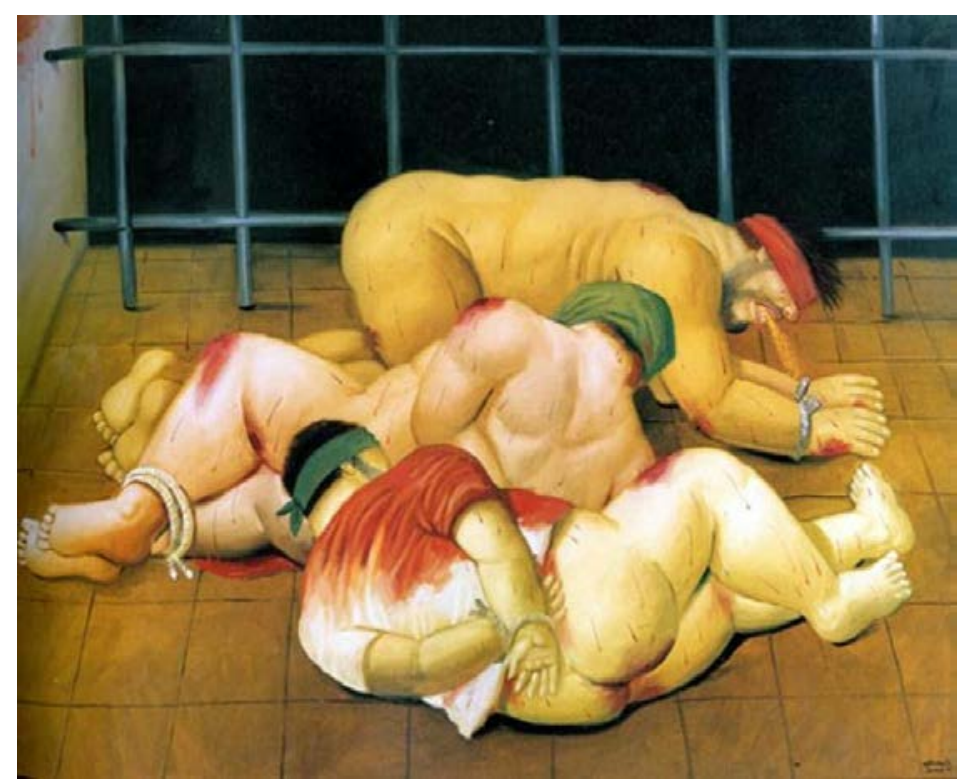

Figure 11 Fernando Botero, Abu Ghrib;2005, oil on canvas , member of Johnno.

\section{Conclusions}

From the above, we can draw some conclusions and recommendations:

1-The artist of the civilizations of the Nile Valley and Mesopotamia are able to make his art reach the direction of the invisible through several features including sanctification and ideal fantasy. It develops the invisible to the levels of absolute through the formation plurality saturated with symbol worlds, modulation by dismantling the clear visible. He could use also the fantasy element by proposing an ideal perfect world away from the temporary world of visible, especially after the invention of writing in $3000 \mathrm{BC}$. An expressive energy and search in imaginary and unmaterial worlds dominate the artistic production by the virtue of the evolution from imagery to symbolism laeding to the opening up in the sphere of metaphysics.

2-The idea of the invisible is maximized with the Arts of Islamic civilization covering its existentialism and compassionate philosophy.

3-The idea of outside and inside in the eastern communities corresponds to the form and content in the Western civilization.

4-Multiplicity of authorities concerning the invisible are multiple in western doctrines and with each artist while the authorities are united in the Islamic and Eastern civilization in general.

5-Divine perspective and spiritual vision of the Eastern civilizations correspond with a complete engineering perspective. It could also destroy it by personal, school or group in western arts seeking into the form and the mysteries of color.

6-The researcher is recommended to continue the purpose of this research by studying well the origins of the history of ancient Egyptian and Arabic arts and the real uncovering of Eastern esoteric ideas drawn from the aesthetics and the merits of the ancient civilizations.

\section{Appendix A.}

Muhyiddin Ibn 'Arabi is one of the world's great spiritual teachers mystic philosopher, poet and sages. He was born in Murcia, Al-Andalus, in 1165. His writings had an immense impact on the Islamic world and even beyond it. The universal ideas underlying his thought are of immediate relevance today.

Maurice Merleau-Ponty's work is commonly associated with the philosophical movement called existentialism, and its intention is to begin with an analysis of the concrete experiences, perceptions, and difficulties of the human existence. However, he never propounded quite the same extreme accounts of radical freedom, beingtowards-death, anguished responsibility and conflicted relations with others, for which existentialism became both famous and notorious in the 1940s and 1950s.

Georg Wilhelm Friedrich Hegel (1770-1831) is one of the greatest systematic thinkers in the history of Western philosophy. In addition to epitomizing German idealist philosophy, Hegel boldly claimed that his own system of 
philosophy represented a historical culmination of all previous philosophical thoughts. Hegel's overall encyclopedic system is divided into the science of Logic, the philosophy of Nature, and the philosophy of Spirit.

Tanagra figures had not been much noted before the end of the 1860s, when ploughmen of Vratsi in Boeotia, Greece, began to uncover tombs ranging in date over many centuries. The main findings, especially from the 4th and 3rd centuries BC, were secured in 1874. Inside and outside the tombs of the Hellenistic period - from the 3rd to the 1st century BC — many small terracotta figures were found. Great quantities that were found in excavation sites at Tanagra identified the city as the source of these figures, which were also exported to distant markets. In addition, such figures were made in many other Mediterranean sites, including Alexandria, Tarentum in Magna Graecia, Centuripe in Sicily and Myrina in Mysia

Abu was a minor god of plants and he was one of the eight deities born to relieve the illness of Tammuz, Enki. Abu means "the father of plants and vegetation." Stephen Langdon has proposed that Abu may have been an ancient name. On the basis, that Abu was identified as the consort of Inanna, the name might not appear in any texts later than the third Dynasty of Ur.

AL-Ghazali is one of the greatest Islamic jurists, theologians, and mystical thinkers. He learned various branches of the traditional Islamic religious sciences in his home town of Tus, Gurgan, and Nishapur in the northern part of Iran. He was also involved in Sufi practices from an early age. Being recognized by Nizam al-Mulk, the vizir of the Seljuq sultans, he was appointed as the head of the Nizamiyyah College at Baghdad in ah 484/ad 1091

Gestalt refers to the concept of the "togetherness" as greater than the sum of its individual parts. It is the total concept of the item being created - rather than just thinking of the separate pieces that make up the item.

The name "Taoism" comes from the Chinese word Taw (pronounced "dow"), which literally means "way" or "path." The Tao is often translated as "the Way of all things," and is conceived as an empty void pregnant with the infinite possibilities of existence. The Tao is beyond the capacity of words to describe and beyond all opposites. As a result, it is often described using intentionally paradoxical languages. The way is like an empty vessel that yet may be drawn from, without ever needing to be filled. It is bottomless; the very progenitor of all things in the world.

Mahmoud Darwish was Born on 13 March 1941 in Al Birweh, a quaint village in the Galilee. He lived a life that is a poignant example of how far talent and determination, combined with a precarious life, can carry an individual from a simple background into the international halls of fame. At the early age of seven, Darwish and his family were forced to flee to Lebanon to escape the ongoing massacres by the Israeli Army that occupied Palestine. The dreadful massacare destroyed Darwish's village (in addition to over 400 other Palestinian villages). Returning -illegally- to their country the following year, he and his family were subjected to the military rule and emergency regulations of the State of Israel, established on expropriated the Palestinian land. They were given the status of "present-absent alien," a status that will mark the poet from that point onwards, preventing him from ever finding his homeland, except in his language and his ever-loving audience.

Fernando Botero is a Colombian painter and sculptor who is known internationally for his highly recognizable style, which has become known as "Boterismo." Botero often visualizes contemporary Latin American life or atrocities—such as the violence of drug wars in his native Colombia, or American abuses of power in his $A b u$ Ghraib series - in his signature style. His portraiture depicts the human form in exaggerated, or inflated proportions. Much of his work can be viewed as political or social critique, yet he has denied any satirical intention with the use of rotund forms. On April 19, 1932, in Medellín, Colombia, Born Fernando Botero Angulo traveled widely during his youth: first, to Bogotá, then to Europe, where got influenced by the masterpieces he saw in Barcelona, Madrid, Florence, and Paris can be seen in his work beginning in the 1960s. Based in Bogotá, Museo Botero is comprised of work from the artist's collection. Botero currently lives and works in Monte Carlo, Monaco with residences in Paris, Pietrasanta, and Evia.

\section{Refrences}

1. Elnajeh, T. (2013, March 30). ** طريــق النجــ* Retrieved August 30, 2017, from http://tareekelnajeh.blogspot.com.eg/2013/03/blogpost_2759.html

2. Sharaf, M. (2013, September 13). أمسام المر آة - محمد شرف. Retrieved August 30, 2017, from https://newspaper.annahar.com/article/66974\%D8\%A3\%D9\%85\%D8\%A7\%D9\%85-\%D8\%A7\%D9\%84\%D9\%85\%D8\%B1\%D8\%A2\%D8\%A9

3. Shehata, R. (2011, February 24). استر اتيجية الحيز الهندسى الجرد فى انبثاق المعانى الروحانية بالفن الاسلامى. Retrieved August 30, 2017, from http://redashehata.blogspot.com.eg/2011/02/blog-post_2506.html

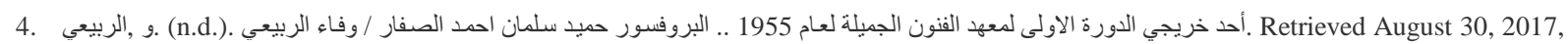
from http://mail.almothaqaf.com/qadaya2009/1955 